\title{
Antibacterial Efficacy Testing of a Bioelectric Wound Dressing Against Clinical Wound Pathogens
}

\author{
Hosan Kim ${ }^{1}$, Inder Makin ${ }^{3}$, Jeff Skiba $^{3}, \mathrm{Amy} \mathrm{Ho}^{3}$, Greggory Housler ${ }^{4}$, Alexander Stojadinovic ${ }^{2,5}$ \\ and Mina Izadjoo ${ }^{1, *}$
}

${ }^{I}$ Diagnostics and Translational Research Center, Henry M Jackson Foundation for the Advancement of Military Medicine, Gaithersburg, MD, USA

${ }^{2}$ Combat Wound Initiative Program, Bethesda, MD, USA

${ }^{3}$ Vomaris, Inc. Vomaris Innovations Inc., Chandler, AZ, USA

${ }^{4}$ United States Army Medical Materiel Agency (USAMMA), Fort Detrick, MD, USA

${ }^{5}$ Walter Reed National Military Medical Center, Bethesda, MD, USA

\begin{abstract}
Silver-based wound dressings have been developed for the control of bioburden in wounds. However, the popularity and extensive use of silver-based dressings has been associated with emerging microbial resistances to silver. In this study we examined in vitro antibacterial efficacy of a bioelectric dressing containing silver and zinc against various wound pathogens. Antibiotic-sensitive clinical wound isolates showed a 100\% reduction in bacterial growth, except that Enterococcus faecalis isolate was shown to survive with a bacterial $\log _{10}$ reduction rate of less than $10^{2} \mathrm{CFU}$. We also investigated antibacterial efficacy against the extended spectrum $\beta$-lactamase (ESBL) bacteria, multidrug-resistant (MDR) bacteria, and methicillin-resistant Staphylococcus aureus (MRSA). The bioelectric dressing was effective in killing wound pathogens including ESBL, MDR, and MRSA in vitro. Furthermore, based on the primary results against E. faecalis, we carried out extensive studies against several nosocomial Enterococcus species including vancomycin-resistant species. Overall, the vancomycin-sensitive or -resistant Enterococcus species were resistant to this dressing at up to $48 \mathrm{~h}$, except for the vancomycin-resistant Enterococcus raffinosus isolate only showing a 100\% bacterial reduction at $48 \mathrm{~h}$, but not at $24 \mathrm{~h}$. The results demonstrated the effective bactericidal activity of a bioelectric dressing against antibiotic-sensitive and MDR strains, but Enterococcus species are bacteriostatic.
\end{abstract}

Keywords: Antibacterial efficacy testing, bioelectric dressing, clinical wound isolates.

\section{INTRODUCTION}

Due to contamination of wounds by single-species or mixed populations of microorganisms leading to colonization and infection, wound healing is seriously impaired. Prevention and control of the microbial burden within wounds have been identified as some of the important aspects of wound management. Antimicrobial dressings, particularly silver-containing wound dressings, are widely used to control the growth of wound pathogens [1-5]. Silverimpregnated wound dressings have been used for treating chronic wounds and have demonstrated consistent antimicrobial activity for a diverse range of wound pathogens [6-8]. In vitro antimicrobial efficacy of various silver-based wound dressings showed varied activities against Gramnegative and -positive bacteria between species and strains.

*Address correspondence to this author at the Diagnostics and Translational Research Center, Henry M Jackson Foundation for the Advancement of Military Medicine, 401 Professional Drive, Suite 210, Gaithersburg, MD, USA; Tel: 240-833-4971; Fax: 240-833-4940;

E-mail: mizadjoo@dtrc-hjfresearch.org.
There have been many reports published on the broadspectrum antimicrobial activity of ionic silver in vitro with greater activity shown against Gram-negative bacteria compared to Gram-positive organisms after $24 \mathrm{~h}$ of bacterial exposure [8]. The antimicrobial activity that exists in silvercoated wound dressings is due to silver's ability to block the energy metabolism functioning across bacterial membranes [9].

Novel approaches to the emerging microbial resistance to antibiotics or other disinfectants have been developed. One such approach is the application of a bioelectric field for control of wound bioburden. Procellera ${ }^{\mathrm{TM}}$ is a sterile, single layer dressing consisting of a matrix of alternating silver ( $\mathrm{Ag})$ and zinc $(\mathrm{Zn})$ dots that are held in position on a polyester substrate with a biocompatible binder. The dressing is activated in the presence of a conductive fluid, which may come from wound exudate or exogenous fluids including saline. When activated, a direct current voltage can be recorded (0.5-0.9 volts) between an $\mathrm{Ag}$ and a $\mathrm{Zn}$ dot. Such a micro-electrical field can potentially augment the natural electric field of injury initiated following skin 
wounding. A physiological current is necessary for the initiation of wound healing and the transport of cells to the healing wound site $[10,11]$. The microbial killing is possibly enhanced first by bioelectric field attracted microbes carrying a negative charge to the positive pole containing silver and zinc. All Gram-negative and -positive microbes carry a negative charge, and are therefore attracted to the positive pole containing silver. Silver then binds to the sulfhydryl groups of the microbes and denatures the proteins that destroy the respiratory function of the microbe as well as other essential proteins within the organism. The interaction of silver ions with thiol groups in bacterial enzymes and proteins plays an essential role in its antimicrobial action, while other cellular components, like hydrogen bonding, may also be involved. In addition, silver ions cause the release of potassium $\left(\mathrm{K}^{+}\right)$ions from bacteria. Hence, the bacterial plasma or cytoplasmic membrane, which is associated with many important enzymes, is an important target site for silver ions [10, 11].

Besides the specific mode of action by silver, coimpregnated zinc may contribute its antimicrobial activity by changing the cell membrane and oxidative stress to some degree as synergistic effects. It has been known that zinc $\left(\mathrm{Zn}^{2+}\right)$ is involved in a wide variety of cellular processes, is required for maintaining the structural stability of macromolecules, and serves as an important cofactor for other enzymes [12]. However, in excess zinc can inhibit the aerobic respiratory chain, can have significant toxicity, and can act as a potent inhibitor of biological systems. In prokaryotes, the major mechanisms that maintain cellular $\mathrm{Zn}^{2+}$ concentrations are limited to the highly regulated processes of $\mathrm{Zn}^{2+}$ import, metal ion sequestration by metallochaperones and $\mathrm{Zn}^{2+}$ export across the cytoplasmic membrane [13]. Yet the molecular basis of zinc toxicity remains poorly understood. Recently, the antibacterial mechanism of zinc nanoparticle in Campylobacter jejuni was determined to be most likely related to disruption of the cell membrane and oxidative stress [14]. Due to a unique characteristic that the bioelectric current is generated by the elements such as Ag$\mathrm{Zn}$, there is also synergistic antimicrobial activity within the intrinsic properties of these elements.

In this study, we examined the in vitro antibacterial response to the composite bioelectric (Ag-Zn) dressing against clinically important bacterial pathogens and against drug-resistant clinical wound isolates, such as Klebsiella pneumoniae (ESBL), Pseudomonas aeruginosa (MDR), MRSA, and vancomycin-resistant Enterococcus species. The results of this study suggest that the combination of silver and zinc ions within a bioelectric dressing may have clinically important effects through its broad bactericidal activity; however, bacteriostatic responses with regard to Enterococcus species warrant further critical appraisal.

\section{MATERIALS AND METHODS}

\section{Bacterial Isolation and Identification}

The microorganisms used in this study were routinely isolated from the wounds of patients treated in the Complex Wound and Limb Salvage Center at Walter Reed National Military Medical Center (Bethesda, MD, USA) and were obtained from the wound pathogen collections in the
Diagnostics and Translational Research Center (DTRC), (Gaithersburg, MD, USA). Clinical isolates, having unknown antibiotic resistance including, Acinetobacter baumannii (4383), Acinetobacter calcoaceticus (W0041-00CS1), Enterococcus faecalis (W0044-13-CS1), Escherichia coli (W0041-00-CS1), Klebsiellapneumoniae (W0043-10CS1), Pseudomonas aeruginosa (6611), Staphylococcus aureus (W0043-10-TS4), Staphylococcus epidermidis (W0040-05-CS1), and controls, P. aeruginosa (ATCC 27853), and S. aureus (ATCC 25923) were selected and used to evaluate the antibacterial properties of the Ag-Zn bioelectric dressing. Multidrug-resistant (MDR) clinical wound isolates, $K$. pneumoniae (325, ESBL), P. aeruginosa (467, MDR), and methicillin-resistant $S$. aureus (507, MRSA) were studied. Clinical Enterococcus species, E. faecalis CI (4413), E. Faecalis (CI 543), E. faecalis vancomycin-resistant enterococcus (VRE17), E. Faecalis (VRE 223), E. Faecium (VRE 48), E. raffinosus(VRE 510), E. Faecalis (ATCC 11823)and E. Faecalis (ATCC 29212) were studied as well. The antibiotic resistance of these Enterococcus species was determined using the BD Phoenix automated microbiology system (BD Diagnostics, Sparks, MD, USA) and Spectra ${ }^{\text {TM }}$ VRE test (Remel, Lenexa, KS) according to the companies' procedures.

\section{Antibiotic Susceptibility}

For primary wound pathogens and any silver and zincresistant isolates, the susceptibility to appropriate antibiotics was tested on IsoSensitest agar (Oxoid, Basing stoke, UK) [5]. All plates were incubated at $37^{\circ} \mathrm{C}$ for $18-24 \mathrm{~h}$. For rapid and convenient identification of Enterococcus species and its vancomycin susceptibility, we used a Spectra ${ }^{\mathrm{TM}}$ VRE test. It is a selective and differential chromogenic medium, containing $6 \mu \mathrm{g} / \mathrm{mL}$ of vancomycin, intended for use in the qualitative detection of vancomycin-resistant $E$. faecium and E. faecalis. According to the manufacturer's protocols, we verified the Enterococcus species and vancomycin susceptibility.

\section{Antibacterial Efficacy Test}

Swatches of test and control textile materials were tested qualitatively for antibacterial activity by Method 147 entitled "Antibacterial Activity Assessment of Textile Materials: Parallel Streak Method (http://www.aatcc.org.)" from the American Association of Textile Chemists and Colorists (AATCC). Those showing activities were evaluated quantitatively. Test and control swatches were inoculated with the test organisms. After incubation, the bacteria were eluted from the swatches by shaking in known volumes of neutralizing solution. The number of bacteria present in this liquid was determined, and the percentage reduction by the treated specimen was calculated. Based on the AATCC Test Method 100-2004 with some modification [15], the antibacterial properties of the bioelectric dressing samples, Procellera $^{\mathrm{TM}}$ (Vomaris, Inc., Chandler, AZ, USA) (http://procellera.com/) were determined. The dressing (2" x 2 " in size) contained $0.9 \mathrm{mg} / \mathrm{cm}^{2}$ silver and $0.3 \mathrm{mg} / \mathrm{cm}^{2}$ zinc. All pathogens studied were streaked onto tryptic soy agar (TSA) (MP Biomedicals, Solon, OH, USA) plates. On the next day, a single colony from each culture was inoculated 
into tryptic soy broth (TSB)(MP Biomedicals, Solon, OH, USA). After overnight incubation at $37^{\circ} \mathrm{C}$, these logarithmic growth phase cultures were diluted $(1: 1,000$ or $1: 10,000)$ into fresh TSB to achieve an approximate concentration of $4 \times 10^{5}$ colony forming units (CFUs) $/ \mathrm{mL}$. The true concentrations were determined by two methods including colony counts on agar plates and the spectrophotometric measurement of the optical density (OD) at OD600nm. The concentration was added to the $4.8 \mathrm{~cm}$-diameter dressings (or equivalent to 2" $\mathrm{x} 2$ " Procellera ${ }^{\mathrm{TM}}$ ). Controls included untreated dressing samples which did not contain silver and zinc, fresh TSB applied directly onto a bioelectric dressing sample, and bioelectric dressing samples plated at " 0 " contact time (plated as soon as possible after inoculation). The bioelectric dressing samples and control samples were incubated in a volumetric flask at $37^{\circ} \mathrm{C}$ for $24 \mathrm{~h}$. At the end of the incubation period, the samples were quenched with $100 \mathrm{~mL}$ PBS supplemented with sodium thioglycolate as a neutralizing solution. Flasks were shaken vigorously for 1 min and serial dilutions of the eluents were made in $0.85 \%$ normal saline solution. Then each dilution was plated onto TSA plates and incubated at $37^{\circ} \mathrm{C}$ for $24 \mathrm{~h}$. The next day viable bacteria were counted. The percentage reduction in the bacterial load was calculated by the following formula:

$\%$ bacterial reduction $=100(\mathrm{~B}-\mathrm{A}) / \mathrm{B}$.

where $\mathrm{A}$ is the CFUs of bacteria recovered from the inoculated bioelectric dressing samples incubated for $24 \mathrm{~h}$, and $\mathrm{B}$ is the CFUs of bacteria recovered from the inoculated bioelectric dressing sample at " 0 " contact time (or inoculated non-silver and zinc coated sample at " 0 " contact time) incubated for $24 \mathrm{~h}$. The percentage reduction was also converted to the $\log _{10}$ reduction values, which represent the antimicrobial effect of the silver and zinc in the dressing. Then they were calculated as the difference between the $\log _{10}$ values of the starting and surviving numbers of microorganisms. Bactericidal activity was defined as a reduction of greater than $10^{3} \mathrm{CFU}$ in a $10^{5} \mathrm{CFU} / \mathrm{mL}$ inoculum. For the prolonged antibacterial efficacy test, the bioelectric dressing samples treated with Enterococcus clinical wound isolates showing a bacteriostatic activity were incubated at $37^{\circ} \mathrm{C}$ for 0,24 , and $48 \mathrm{~h}$. All experiments were carried out in three independent assays.

\section{Detection of Silver Resistance Genes}

To investigate whether any of the strains carried genes encoding silver resistance (silE, silP and silS), a colony PCR assay for silver-resistant colonies with silE $(0.4 \mathrm{~kb})$, silP $(2.5$ $\mathrm{kb})$, and sil $\mathrm{S}(1.5 \mathrm{~kb})$ primer sets was performed [5, 16]. Templates were prepared by heating a bacterial suspension at $95^{\circ} \mathrm{C}$ for $10 \mathrm{~min}$. Each PCR reaction contained $2 \mu \mathrm{L}$ template DNA, $0.4 \mu \mathrm{L}$ respective primer pair and $1 \mu \mathrm{L}$ Taq DNA polymerase (New England Biolabs, Ipswich, MA, USA) for a total reaction volume of $20 \mu \mathrm{L}$.

The mixtures were processed in a Bio-Rad cycler, consisting initial denaturation at $95^{\circ} \mathrm{C}$ for $2 \mathrm{~min}$, followed by 40 cycles of $1 \mathrm{~min}$ at $95^{\circ} \mathrm{C}, 1 \mathrm{~min}$ at $55^{\circ} \mathrm{C}$, and $3 \mathrm{~min}$ at $72^{\circ} \mathrm{C}$. The final extension step was performed at $72^{\circ} \mathrm{C}$ for 5 min. As positive and negative controls, Enterobacter cloacae ATCC 13047 (carrier of the complete sil gene complex) and $\mathrm{dH}_{2} \mathrm{O}$ were included. Each DNA sample was run twice. Ten $\mu \mathrm{L}$ of each PCR reaction was analyzed on a $1.2 \%$ agarose gel. After electrophoresis was completed, the gel was photographed and the bands were analyzed.

\section{Statistical Analysis}

Data were expressed as mean \pm standard deviation. Statistical comparisons were performed using as a two-tailed $\mathrm{t}$-test assuming equal variances, where $\mathrm{P}$-values $<0.05$ were considered statistically significant.

\section{RESULTS}

\section{Characterization of Wound Pathogens}

Clinical wound isolates having unknown antibiotic resistance were selected and used to evaluate antibacterial properties of the Ag-Zn bioelectric dressings (Fig. 1). Next, to determine antibacterial efficacy against the antibioticresistant clinical wound isolates we selected the MDR, ESBL, and MRSA (Fig. 1). Furthermore, to determine whether this wound dressing has bactericidal or bacteriostatic activity against other Enterococcus species, clinically relevant Enterococcus species were tested, as shown in Fig. (2) and Table 1.

Multidrug-resistant clinical isolates and vancomycin resistance of these Enterococcus species were identified by the BD Phoenix automated microbiology system. The resistance of all the Enterococcus species tested in this study was verified again using a commercial identification kit, Spectra ${ }^{\mathrm{TM}}$ VRE test. The system is designed for E. faecalis and E. facieum strains. Each strain shows a blue or pink color when it is grown on the agar plate. As expected the $E$. faecalis and E. faecium VRE isolates fully grew (blue and pink, respectively) on the assay plates containing $6 \mu \mathrm{g} / \mathrm{mL}$ vancomycin, indicating that they are resistant to vancomycin. Other isolates (E. facalis CI 4413, E. faecalis CI 543 isolates, and even controls such as E. faecalis ATCC 11823 and E. faecalis ATCC 29212 strains) showed partial growth in blue, indicating that they have a MIC $\geq 6 \mu \mathrm{g} / \mathrm{mL}$ and possibly have intermediate sensitivity or are sensitive to vancomycin. Later it was determined to be sensitive to vancomycin based on the BD Phoenix instrument. No $E$. raffinosus isolate was grown up to $48 \mathrm{~h}$ incubation (data not shown). Most of the Enterococcus strains were shown to be vancomycin-resistant, although the susceptibility of these strains varied.

\section{Antibacterial Efficacy of a Bioelectric Wound Dressing}

Except for the E. faecalis isolates, all types of clinical bacterial isolates were killed completely within $24 \mathrm{~h}$ of exposure to the bioelectric wound dressing (Fig. 1). We selected several multidrug-resistant strains, such as $K$. pneumonia MDR, MRSA and $P$. aeruginosa MDR. All of these MDR strains had shown a $100 \%$ reduction at $24 \mathrm{~h}$, indicating the dressing has broad-spectrum bactericidal activity (Fig. 1). Eight additional clinical Enterococcus species including VRE isolates were selected, and the antibacterial efficacy of the dressings against these species was extensively examined (Fig. 2 and Table 1). Unexpectedly, the results showed approximately 100 -fold increases at 


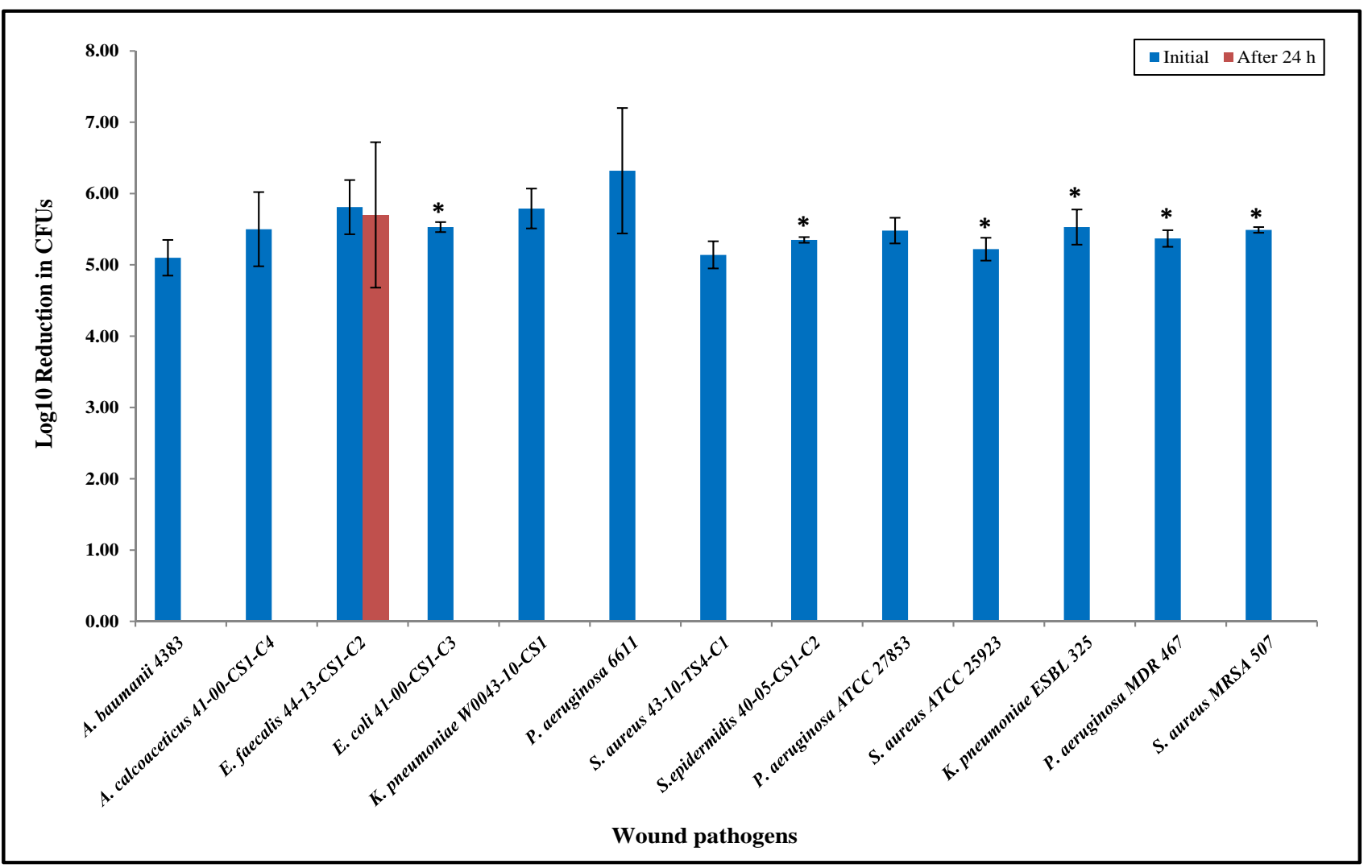

Fig. (1). Antibacterial properties of the bioelectric wound dressing showing $\log 10$ reduction in CFU of bacteria after $24 \mathrm{~h}$ exposure against various clinical wound isolates. The numbers of the bioelectric wound dressing treated bacteria at $24 \mathrm{~h}$ were significantly lower when compared to the control treated at 0 hour $(* \mathrm{P}<0.05)$ as denoted with asterisk. Data reported are the average values of three independent assays. The results are shown as means the standard error on the mean of three experiments.

Table 1. Enterococcus clinical isolates from wounds, antibiotic resistance, and antibacterial efficacy to the bioelectric wound dressing.

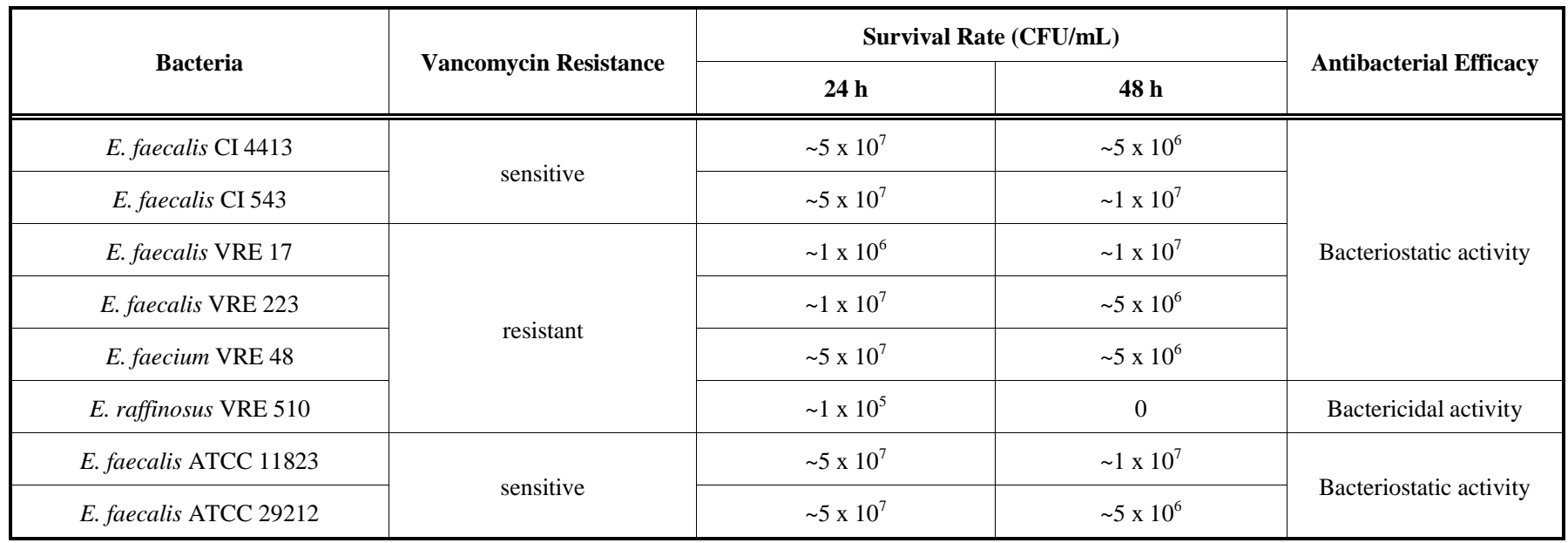

$24 \mathrm{~h}$ compared to the starting inoculum applied to the bioelectric dressing at $0 \mathrm{~h}$ (approximately $4 \times 10^{5} \mathrm{CFU} / \mathrm{mL}$ ). It was determined that the effect of the bioelectric dressing against most of the VRE clinical isolates was bacteriostatic at $24 \mathrm{~h}$ having almost similar bacterial survival rates (Fig. 2 and Table 1).

\section{Prolonged Incubation with the Wound Dressing Treatment}

Potential bacteriostatic Enterococcus isolates at $24 \mathrm{~h}$ were tested to determine how such isolates would react to longer incubation times of up to $48 \mathrm{~h}$. Each bacterial culture was applied to bioelectric wound dressings. The cultures 


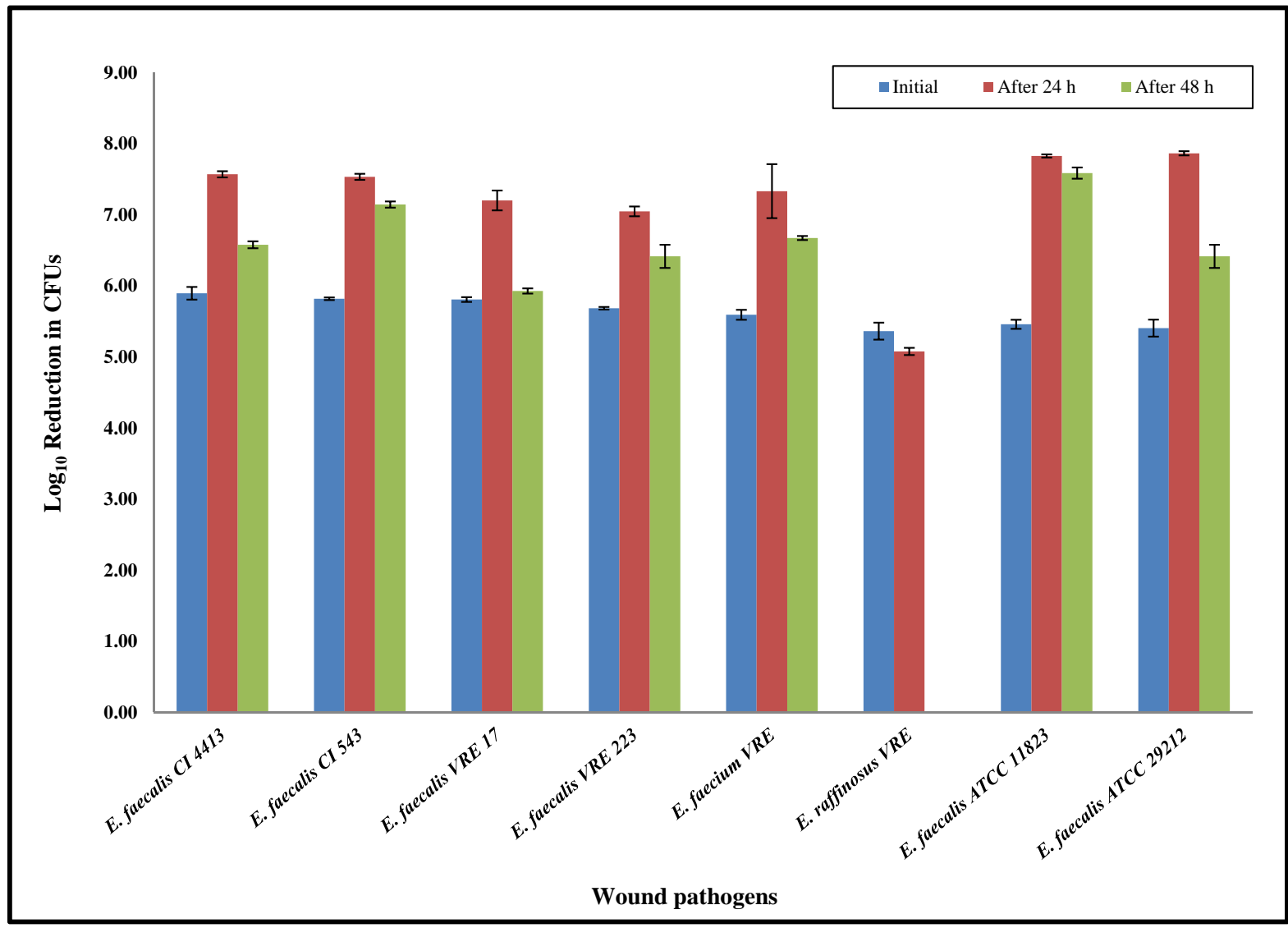

Fig. (2). Prolonged incubation up to 48 hours showing the antibacterial properties of the bioelectric wound dressing against Enterococcus clinical wound isolates. Data reported are the average values of three independent assays. The results are shown as means the standard error on the mean of three experiments.

were then incubated at $37^{\circ} \mathrm{C}$ for 24 or $48 \mathrm{~h}$, respectively. After 24 or $48 \mathrm{~h}$ incubation, colonies were counted to calculate antibacterial efficacy. All the Enterococcus bacterial isolates had slightly decreased growth at $48 \mathrm{~h}$ compared with those exposed to the bioelectric wound dressing for $24 \mathrm{~h}$. However, an E. raffinosus VRE isolate showed no growth, and $100 \%$ bacterial reduction within 48 h. The data showed that the bioelectric wound dressing could have a specific bactericidal activity against the E. raffinosus VRE isolate. Percival et al. [15] showed that all strains were killed following a maximum of $48 \mathrm{~h}$ of exposure to the dressings. However, in this study, most of the Enterococcus species, with the exception of E. raffinosus VRE, showed no significant response (antimicrobial effect) to the bioelectric wound dressing even up to $48 \mathrm{~h}$ (Fig. 2 and Table 1). Although bacteriostatic activity was evident at $24 \mathrm{~h}$ for $E$. raffinosus VRE, prolonged incubation up to $48 \mathrm{~h}$ was effective in $100 \%$ killing with the dressing exposure. This difference may have resulted due to the generally slow bacterial growth rate of $E$. raffinosus VRE isolate, such that antibacterial activity of the dressing may be time dependent.

\section{PCR Analysis for Detection of Silver-Resistant genes}

To determine any associations with the known silverresistant proteins, we tested the presence of silver-resistant genes in Enterococcus isolates in PCR analysis. None of the PCR products representing the silver-resistant genes were found in any of the tested organisms, except the E. cloacae control strain which was found to possess all three genes (data not shown).

\section{DISCUSSION}

This study was designed to assess the in vitro antibacterial activity of an advanced wound care bioelectric $(\mathrm{Ag}-\mathrm{Zn})$ dressing. Quantitative antibacterial in vitro testing was used to conduct this investigation. The bioelectric wound dressing showed a good bacterial killing activity against Gram-negative and -positive bacteria as shown in Fig. (1). Because of the initial bacteriostatic activity observed against the E. faecalis clinical isolate (Fig. 1), eight additional clinical Enterococcus species were selected and examined for their antibacterial efficacy. Unexpectedly, the results showed approximately 100 -fold increases at $24 \mathrm{~h}$ and subsequently 10 -fold reduction at $48 \mathrm{~h}$ compared to the starting inoculum at $0 \mathrm{~h}$ (approximately $4 \times 10^{5} \mathrm{CFU} / \mathrm{mL}$ ) that was applied to the bioelectric dressing. Enterococci tested after $24 \mathrm{~h}$ exposure to the wound dressing showed an increase of approximately $1 \times 10^{7} \mathrm{CFU} / \mathrm{mL}$, indicating the prevalence of $(\mathrm{Ag}-\mathrm{Zn})$ resistance in Enterococcus species. This resistance might be due to intrinsic characteristics in 
cell wall and membrane to some degree (Fig. 2 and Table 1). In the comparative antimicrobial efficacy studies of various wound dressings, it was reported that a certain type of MRSA and B. subtilis among $S$. aureus, $P$. aeruginosa, and E. coli are less sensitive to the tested antimicrobial dressings [17]. It suggests that some dressings have a narrower range of bactericidal activities against both Gram-positive and negative bacteria, but others exert a broad spectrum of action because the activity of the agents impregnated in wound dressings may vary depending on the total amount, method of impregnation, dressing properties and sustained availability. Additionally, results may be influenced by dressings binding with components of wound fluid, negating its antimicrobial attributes during clinical use [18]. Nevertheless, some particular dressings may be less sensitive to multidrug-resistant and/or (Ag-Zn)-resistant bacteria. Future extensive studies are planned with prolonged incubation up to 7 days and application of various comparable wound dressings including either $\mathrm{Ag}$ or $\mathrm{Zn}$ or both, as tested in the present study. In the case of $E$. raffinosus VRE, this species had an approximately $1 \times 10^{5} \mathrm{CFU} / \mathrm{mL}$ at $24 \mathrm{~h}$ (Table 1). Surprisingly, the bioelectric wound dressing showed bacteriostatic activity at $24 \mathrm{~h}$ incubation to E. raffinosus, but it had bactericidal activity at 48 h. E. raffinosus VRE only had bactericidal activity, which may be due to its slow growth. Therefore, gene expression levels of other Enterococcus isolates and the E. raffinosus VRE isolate may be a topic for further investigation.

Enterococci, Gram-positive lactic acid bacteria, are prevalent in the environment, and are an important source of nosocomial infections, as well as wound infections and endocarditis. Certain enterococcal strains, such as E. faecalis and E. faecium, are becoming increasingly harmful to people with weakened immune systems since bacteria within such individuals are intrinsically resistant to many antibiotics including cephalosporins, quinolones, clindamycin, and can easily acquire additional antimicrobial resistance. At present, the increasing occurrence of VRE is a particularly important clinical concern, as effective antibiotic treatment can be difficult to achieve. Therefore, understanding resistance to antibiotics and biocides is a topic of major significance. Vancomycin-resistant clinical isolates of Enterococcus species are now commonly diagnosed in clinical microbiology laboratories. In contrast to Enterococcus spp., S. aureus isolates are susceptible to vancomycin. There is growing concern that there is emerging vancomycin resistance for this bacterial species [19]. Recently, several cases of high-level resistance to vancomycin among $S$. aureus (VRSA, MIC $\geq 16 \mu \mathrm{g} / \mathrm{mL}$ ) and vancomycin-intermediate $S$. aureus (VISA, MICs $4-8 \mu \mathrm{g} / \mathrm{mL}$ ) were reported [20-22]. Our future studies will focus on the in vitro antibacterial efficacy test against VISAs and VRSAs using several types of wound dressings, including the one tested in this study.

As Silver [23] suggested, the widespread and uncontrolled use of $\mathrm{Ag}^{+}$in wound care may result in more bacteria developing resistance. Furthermore, Li et al. [24] described $\mathrm{Ag}^{+}$-resistant clinical E. coli isolates, selected by step-wise exposure to higher concentrations of $\mathrm{Ag}^{+}$, demonstrating active efflux of $\mathrm{Ag}^{+}$. In our study, we found in vitro bacteriostatic activity against several Enterococcus species, indicating the bacterial evolution to silver resistance (Fig. 2 and Table 1). The activity is not directly derived from the genes encoding either silver or zinc resistance. However, it might be from the genes capable of altering cell membrane rigidity and integrity, because in the PCR analysis for detecting the known silver-resistance genes, no PCR products were produced except for E. cloacae ATCC 13047 as a control (data not shown), indicating no presence of sil genes in the Enterococcus isolates investigated. The existence of a silver-resistance gene (silE) in MRSA and MR-CNS did not provide protection to the organism with a silver-containing hydro-fiber wound dressing [25]. To date, no MRSA strains have been found to possess silverresistance genes. Such a result gives reason to believe that the resistance of Enterococcus species to ( $\mathrm{Ag}-\mathrm{Zn})$, which is impregnated in the bioelectric wound dressing, might be due to tight regulation or changes in structure of influx and efflux processes necessary to maintain the intracellular level of the heavy metal ions. Overall, these results indicate that the (AgZn)-resistant Enterococcus species might develop tolerance through other mechanisms.

Currently, there is no known, common mechanism of bacterial resistance to all heavy metal ions. Usually, the genes encoding resistance to heavy metals are located either on the chromosome, on the plasmids, or on both in bacteria. Bacteria have evolved mechanisms utilizing a number of proteins, such as ion transporters, reductases, glutathionerelated cadystines, cysteine-rich metallothioneins, and lowmolecular-weight cysteine-rich metal ligands to regulate the influx and efflux processes necessary to maintain the intracellular level of the heavy metal ions [26]. According to a recent publication, most silver-resistant bacterial strains have developed tolerance by utilizing an $\mathrm{Ag}^{+}$ATPase efflux pump and anti-porters rather than chemical detoxification mechanisms in which the genes encoding for copper-silver efflux outer membrane protein, and periplasmic copper and silver binding proteins were up-regulated when the bacteria were exposed to silver nanoparticles [4]. The work indicated that multiple antibiotic resistance genes may also play a role in the evolution of silver resistance in E. coli. Recently, to understand the molecular basis for the high zinc resistance, Xiong et al. [27] performed whole genome sequencing and identified nine putative $\mathrm{Zn}^{2+}$ transporters with four zntA-like genes among them being all induced by $\mathrm{Zn}^{2+}$ and $\mathrm{ZntR} 1$ (a regulator for transcription of $z n t \mathrm{~A} 1$ ). Due to the lack of understanding of silver or zinc regulation in the Enterococcus species, current research efforts are focused on finding genes up-regulated and down-regulated under $(\mathrm{Ag}-$ $\mathrm{Zn}$ ) exposure in order to understand how these Enterococcus species cope with either $\mathrm{Ag}$ or $\mathrm{Zn}$, or both in environmental stresses.

Through extensive characterization of the (Ag-Zn)resistant mutants of Enterococcus species, or through further selection by stepwise exposure of both sensitive and resistant strains to either $\mathrm{AgNO}_{3}, \mathrm{ZnCl}_{2}$, or in combination with both species, any enhanced efflux of $(\mathrm{Ag}-\mathrm{Zn})$ ions will be examined to see if (Ag-Zn)-resistant mutants are found. We hypothesize that (Ag-Zn) resistance in Enterococcus species may depend on the activation of endogenous silver and/or zinc efflux systems while providing the basis for $(\mathrm{Ag}-\mathrm{Zn})$ resistance, as described in Candida albicans [28]. Future 
studies are planned to pursue and identify the mechanism of (Ag-Zn) resistance and the stability of the resistance phenotype in the absence of (Ag-Zn) selection pressure.

\section{CONCLUSION}

The effective bactericidal activity of a bioelectric wound dressing was shown against antibiotic-sensitive strains and multiple antibiotic-resistant strains of wound pathogens, but Enterococcus species including VRE strains are bacteriostatic when exposed to the wound dressing. We hypothesize that (Ag-Zn) resistance in Enterococcus species may depend on the activation of endogenous silver and/or zinc efflux systems while providing the basis for $(\mathrm{Ag}-\mathrm{Zn})$ resistance.

\section{DISCLAIMER}

The opinions or assertions contained herein are the private views of the authors, based on scientific investigation, and are not to be construed as official or as reflecting the views of the US Department of the Army, the Department of Defense, the Department of Veterans Affairs, or the Henry M. Jackson Foundation.

\section{CONFLICT OF INTEREST}

The authors confirm that this article content has no conflicts of interest.

\section{ACKNOWLEDGEMENT}

This study was supported by the Air Force Medical Support Agency (AFMSA). Our gratitude goes to the US Air Force Office of Surgeon General for their vision and support of research projects aimed at improving military medicine.

\section{REFERENCES}

Powler PG, Jones SA, Walker M, Parsons D, Microbiocidal properties of a silver-containing hydrofiber dressing against a variety of burn wound pathogens. J Burn Care Rehabil 2004; 25:192-6.

[2] Ip M, Lui SL, Poon VK, Lung I, Burd A. Antimicrobial activities of silver dressings: an in vitro comparison. J Med Microbiol 2006; 55: 59-63.

[3] Chopra I. The increasing use of silver-based products as antimicrobial agents: a useful development or a cause for concern? J Antimicrob Chemother 2007; 59: 587-90.

[4] Nagy A, Harrison A, Sabbani S, Munson RS Jr, Dutta PK, Waldman WJ. Silver nanoparticles embedded in zeolite membranes: release of silver ions and mechanism of antibacterial action. Int J Nanomed 2011; 6:1833-52.

[5] Sütterlin S, Tano E, Bergsten A, Tallberg AB, Melhus A. Effects of silver-based wound dressings on the bacterial flora in chronic leg ulcers and its susceptibility in vitro to silver. Acta Derm Venereol 2011; 92: 34-9.

[6] Caruso DM, Foster KN, Hermans MH, Rick C. Aquacel Ag in the management of partial-thickness burns: results of a clinical trial. $\mathrm{J}$ Burn Care Rehabil 2004; 25: 89-97.
[7] Beele H, Meuleneire F, Nahuys M, Percival SL. A prospective randomised open label study to evaluate the potential of a new silver alginate/carboxymethylcellulose antimicrobial wound dressing to promote wound healing. Int Wound J 2010; 7: 262-70.

[8] Hooper SJ, Williams DW, Thomas DW, Hill KE, Percival SL. An in vitro comparison of two silver-containing antimicrobial wound dressings. Ostomy Wound Manage 2012; 58:16-22.

[9] Heggers J, Goodheart RE, Washington J, et al. Therapeutic efficacy of three silver dressings in an infected animal model. J Burn Care Rehabil 2005; 26: 53-6.

[10] Blount AL, Foster S, Rapp DA, Wilcox R. The use of bioelectric dressings in skin graft harvest sites: A Prospective case series. J Burn Care Res 2012; 33: 354-7.

[11] Harding AC, Gil J, Valdes J, Solis M, Davis SC. Efficacy of a bioelectric dressing in healing deep, partial-thickness wounds using a porcine model. Ostomy Wound Manage 2012; 58: 50-5.

[12] McCall KA, Huang C, Fierke CA. Function and mechanism of zinc metalloenzymes. J Nutr 2000; 130: 5S Suppl, 1437S-46S.

[13] Blencowe DK, MorbyAP. Zn(II) metabolism in prokaryotes. FEMS Microbiol Rev 2003; 27: 291-311.

[14] Xie Y, He Y, Irwin PL, Jin T, Shi X. Antibacterial activity and mechanism of action of zinc oxide nanoparticles against Campylobacter jejuni. Appl Environ Microbiol 2011; 77: 2325-31.

[15] Kulthong K, Srisung S, Boonpavanitchakul K, Kangwansupamonkon W, Maniratanachote R. Determination of silver nanoparticle release from antibacterial fabrics into artificial sweat. Part Fibre Toxicol 2010; 7: 8-16.

[16] Percival SL, Woods E, Nutekpor M, Bowler P, Radford A, Cochrane C. Prevalence of silver resistance in bacteria isolated from diabetic foot ulcers and efficacy of silver-containing wound dressings. Ostomy Wound Manage 2008; 54: 30-40.

[17] Aramwit P, Muangman P, Namviriyachote N, Srichana T. In vitro evaluation of the antimicrobial effectiveness and moisture binding properties of wound dressings. Int J Mol Sci 2010; 11: 2864-74.

[18] Werthén M, Davoudi M, Sonesson A, et al. Pseudomonas aeruginosa-induced infection and degradation of human wound fluid and skin proteins ex vivo are eradicated by a synthetic cationic polymer. J Antimicrob Chemother 2004; 54: 772-9.

[19] Perez F, Salata RA, Bonomo RA. Current and novel antibiotics against resistant Gram-positive bacteria. Infect Drug Resist 2008; 1: 27-44.

[20] Sievert DM, Rudrik JT, Patel JB, McDonald LC, Wilkins MJ, Hageman JC. Vancomycin-resistant Staphylococcus aureus in the United States, 2002-2006. Clin Infect Dis 2008; 46: 668-74.

[21] Chang S, Sievert DM, Hageman JC. Infection with vancomycinresistant Staphylococcus aureus containing the vanA resistance gene. N Engl J Med 2003; 348:1342-7.

[22] Smith TL, Pearson ML, Wilcox KR. Emergence of vancomycin resistance in Staphylococcus aureus. Glycopeptide-Intermediate Staphylococcus aureus Working Group. N Engl J Med 1999; 340: 493-501.

[23] Silver S. Bacterial silver resistance: molecular biology and uses and misuses of silver compounds. FEMS Microbiol Rev 2003; 27: 34153.

[24] Li XZ, Nikaido H, Williams KE. Silver-resistant mutants of Escherichia coli display active efflux of $\mathrm{Ag}^{+}$and are deficient in porins. J Bacteriol1997; 179: 6127-32

[25] Loh JV, Percival SL, Woods EJ, Williams, NJ, Cochrane CA. Silver resistance in MRSA isolated from wound and nasal sources in humans and animals. Int Wound J 2009; 6: 32-8.

[26] Silver S, Phung LT. Bacterial heavy metal resistance: new surprises. Annu Rev Microbiol 1996; 50:753-89.

[27] Xiong J, Li D, Li H, et al. Genome analysis andcharacterization of zinc efflux systems of a highly zinc-resistant bacterium, Comamonastestosteroni S44. Res Microbiol 2011; 162: 671-9.

[28] Riggle PJ, Kumamoto CA. Role of a Candida albicans P1-type ATPase in resistance to copper and silver ion toxicity. J Bacteriol 2000; 182: 4899-905. 